\title{
Enzymatic synthesis of polymers containing nicotinamide mononucleotide
}

\author{
Rihe Liu and Leslie E. Orgel ${ }^{*}$
}

The Salk Institute for Biological Studies, PO Box 85800, San Diego, CA 92186-5800, USA

Received May 15, 1995; Revised and Accepted August 9, 1995

\begin{abstract}
Nicotinamide mononucleoside 5 -diphosphate in its reduced form is an excellent substrate for polynucleotide phosphorylase from Micrococcus luteus both in de novo polymerization reactions and in primer extension reactions. The oxidized form of the diphosphate is a much less efficient substrate; it can be used to extend primers but does not oligomerize in the absence of a primer. The cyanide adduct of the oxidized substrate, like the reduced substrate, polymerizes efficiently. Loss of cyanide yields high molecular weight polymers of the oxidized form. Terminal transferase from calf thymus accepts nicotinamide mononucleoside 5 '-triphosphate as a substrate and efficiently adds one residue to the $3^{\prime}$-end of an oligodeoxynucleotide. T4 polynucleotide kinase accepts oligomers of nicotinamide mononucleotide as substrates. However, RNA polymerases do not incorporate nicotinamide mononucleoside 5'-triphosphate into products on any of the templates that we used.
\end{abstract}

\section{INTRODUCTION}

It is now well-established that RNA catalysts, ribozymes, can bring about many hydrolysis and group-transfer reactions (I-6). It has been speculated that the nicotinamide co-enzymes may be fossils of an RNA world, in which they were co-factors that extended the range of RNA-catalyzed reactions to include redox reactions $(7,8)$. While it has usually been supposed that the co-enzymes were attached to RNA by hydrogen-bonding and other non-covalent interactions, the incorporation of nicotinamide mononucleotide $\left(\mathrm{NMN}^{+}\right)$within or at the end of RNA molecules is also feasible. The possibility that nicotinamide could substitute for adenine or guanine in a Watson-Crick base-pair (Fig. 1) suggests that template-directed incorporation of $\mathrm{NMN}^{+}$ into an oligonucleotide might be possible.

In this paper we show that polymers of $\mathrm{NMN}^{+}$and of reduced nicotinamide mononucleotide (NMNH) can be prepared using polynucleotide phosphorylase from Micrococcus luteus (PNPase). In addition, we show that a single $\mathrm{NMN}^{+}$residue can be added to the 3 -terminus of an oligodeoxynucleotide using terminal transferase from calf thymus. We have not been able to demonstrate template-directed reactions of $\mathrm{NMN}^{+}$derivatives with RNA polymerases or in non-enzymatic systems.

\section{MATERIALS AND METHODS}

\section{Materials}

All chemicals were reagent grade and were used without further purification. Nicotinamide mononucleotide was prepared from nicotinamide adenine dinucleotide $\left(\mathrm{NAD}^{+}\right)$by non-enzymatic hydrolysis with $\mathrm{Zr}^{4+}$ (9). Adenosine 5'-phosphoro(2-methyl) imidazolide (2-MeImpA), uridine 5'-phosphoro(2-methyl)imidazolide (2-MeImpU), cytidine 5'-phosphoro(2-methyl)imidazolide (2-MeImpC), guanosine 5 -phosphoro(2-methyl)imidazolide (2-MelmpG) and nicotinamide mononucleoside 5'-phosphoro(2-methyl)imidazolide (2-MeImpNMN $\left.{ }^{+}\right)$were prepared by a published procedure (10).

Polynucleotide phosphorylase was obtained from Boehringer Mannheim, terminal deoxynucleotidyl transferase from Bethesda Research Laboratories, T4 polynucleotide kinase from New England Biolabs and T3 RNA polymerase, T7 RNA polymerase, ribonuclease $\mathrm{A}$, ribonuclease $\mathrm{T} 1$, ribonuclease $\mathrm{P} 1$, and phosphodiesterase I from United States Biochemicals. $\left[\alpha-{ }^{32}\right.$ P]UTP, $\left[\alpha{ }^{32} \mathrm{P}\right] G T P$ and $\left[\gamma^{32} \mathrm{P}\right]$ ATP were obtained from Amersham.

\section{Oligonucleotides}

Oligodeoxyribonucleotides were synthesized on an Applied Biosystem Model 391A DNA synthesizer using 2-cyanoethyl phosphoramidites. Oligomers terminated by a ribonucleotide at their $3^{\prime}$-ends were synthesized and deprotected following the standard DNA synthesis procedures, using a solid support derivatized with a ribonucleotide (Biosearch). All oligonucleotides were purified on preparative $20 \%$ polyacrylamide gels. The concentrations of single-stranded oligomers were determined from their absorption at $260 \mathrm{~nm}$ using the following molar extinction coefficients: 15400 (A), 11700 (G), 7300 (C) and 8800 (T). ${ }^{32}$ P-labelling was carried out by standard methods (11) using [ $\gamma^{32}$ P]ATP and T4 polynucleotide kinase.

\section{Chromatography}

Low molecular weight products were separated by thin layer chromatography (TLC) on Silica gel $60 \mathrm{~F}_{254}$ from Merck Darmstadt. The solvent systems were: (A) n-PrOH: $\mathrm{NH}_{4} \mathrm{OH}: \mathrm{H}_{2} \mathrm{O}$ 22:4:14; (B) 95\% EtOH:1 M NH${ }_{4} \mathrm{OAc}$, at pH 5.0, 7:3. Larger

\footnotetext{
${ }^{*}$ To whom correspondence should be addressed
} 

scale separations were carried out by descending paper chromatography on Whatman $3 \mathrm{MM}$ paper using solvent systems $\mathrm{A}$ and B.

\section{Gel electrophoresis}

Electrophoresis was carried out using $0.75 \mathrm{~mm}$ thick polyacrylamide gels $(10-20 \%)$, and run at $1000 \mathrm{~V}(-15 \mathrm{~mA})$ for $3-5 \mathrm{~h}$. The gels were autoradiographed with Kodak XAR-5 film at $-70^{\circ} \mathrm{C}$.

\section{NMR analysis}

NMR spectra were recorded on a GE QE-300 NMR using $\mathrm{D}_{2} \mathrm{O}$ (pD 10.8) as solvent. The $\left.\mid{ }^{1} \mathrm{H}\right]$ chemical shifts were referenced to 3 -(trimethylsilyl) propionate (TMSP) and the $\left[{ }^{31} \mathrm{P}\right]$ chemical shifts were referenced to $\mathrm{H}_{3} \mathrm{PO}_{4}$.

\section{Synthesis of $5^{\prime}$-diphosphate and $5^{\prime}$-triphosphate of} $\mathrm{NMN}^{+}\left(\mathrm{NMNDP}^{+}\right.$and $\left.\mathrm{NMNTP}^{+}\right)$

$\mathrm{NMNDP}^{+}$and $\mathrm{NMNTP}^{+}$were prepared from $\mathrm{NMN}^{+}$by the procedure described by Hoard and Ott (12). The reactions were monitored by TLC $\left(\mathrm{NMN}^{+}: \mathrm{R}_{\mathrm{f}}=0.28 ; \mathrm{NMNDP}^{+}: \mathrm{R}_{\mathrm{f}}=0.12\right.$; NMNTP $^{+}: R_{f}=0.09$, solvent $B$ ). The products were separated on a column of DEAE-Sephadex using a linear gradient of triethylammonium hydrogen carbonate as eluent. The resulting oil was dissolved in methanol and added to a $0.2 \mathrm{M}$ solution of $\mathrm{NaClO}_{4}$ in acetone. The precipitated sodium salt was collected by centrifugation, washed with acetone and ether and dried over phosphorous pentoxide. The purity of the products was established by paper chromatography using the Hanes-Isherwood reagent as visualizing agent (13).

$\mathrm{NMNDP}^{+}$: UV $\left(\mathrm{H}_{2} \mathrm{O}, \mathrm{pH} 5.0\right) \lambda_{\max }=266 \mathrm{~nm}(\log \varepsilon=3.62)$

$\left[{ }^{1} \mathrm{H}\right] \mathrm{NMR}\left(\mathrm{D}_{2} \mathrm{O}, \mathrm{pD} 10.8\right) \delta=4.35\left(\mathrm{~m}, 5^{\prime}-\mathrm{H}_{2}\right) ; 4.54-4.70(\mathrm{~m}$, $\left.2^{\prime}-\mathrm{H}, 3^{\prime}-\mathrm{H}, 4^{\prime}-\mathrm{H}\right) ; 6.20\left(\mathrm{~d}, \mathrm{~J}=4.6 \mathrm{~Hz}, 1^{\prime}-\mathrm{H}\right) ; 8.31$ (pt, 5-H); 8.96 (d, J = 8.1 Hz, 4-H); $9.31(\mathrm{~d}, \mathrm{~J}=6.1 \mathrm{~Hz}, 6-\mathrm{H}) ; 9.48(\mathrm{~s}, 2-\mathrm{H})$.

$\left[{ }^{31} \mathrm{P}\right] \mathrm{NMR}\left(\mathrm{D}_{2} \mathrm{O}, \mathrm{pD} 10.8\right) \delta=-5.25(\mathrm{~d}, \mathrm{~J}=22 \mathrm{~Hz}, \beta-\mathrm{P}),-10.12$ (d, $J=22 \mathrm{~Hz}, \alpha-P$ ).

NMNTP+: UV $\left(\mathrm{H}_{2} \mathrm{O}, \mathrm{pH} 5.0\right) \lambda_{\max }=266 \mathrm{~nm}(\log \varepsilon=3.72)$.

$\left[{ }^{\mathrm{l}} \mathrm{H}\right] \mathrm{NMR}\left(\mathrm{D}_{2} \mathrm{O}, \mathrm{pD} 10.8\right) \delta=4.34\left(\mathrm{~m}, 5^{\prime}-\mathrm{H}_{2}\right) ; 4.54-4.70(\mathrm{~m}$, $\left.2^{\prime}-\mathrm{H}, 3^{\prime}-\mathrm{H}, 4^{\prime}-\mathrm{H}\right) ; 6.15\left(\mathrm{~d}, \mathrm{~J}=5.3 \mathrm{~Hz}, \mathrm{l}^{\prime}-\mathrm{H}\right) ; 8.31$ (pt, 5-H); 8.92 $(\mathrm{d}, \mathrm{J}=8.0 \mathrm{~Hz}, 4-\mathrm{H}) ; 9.27(\mathrm{~d}, \mathrm{~J}=6.2 \mathrm{~Hz}, 6-\mathrm{H}) ; 9.43(\mathrm{~s}, 2-\mathrm{H})$.

[ $\left.{ }^{3} \mathrm{P}\right] \mathrm{NMR}\left(\mathrm{D}_{2} \mathrm{O}, \mathrm{pD} 10.8\right) \delta=-4.46(\mathrm{~d}, \mathrm{~J}=20 \mathrm{~Hz}, \gamma-\mathrm{P}),-20.93$ $(\mathrm{t}, \mathrm{J}=20 \mathrm{~Hz}, \beta-\mathrm{P}),-10.67(\mathrm{~d}, \mathrm{~J}=10 \mathrm{~Hz}, \alpha-\mathrm{P})$.

\section{Reduction of NMNDP ${ }^{+}$and $\mathrm{NMNTP}^{+}$and preparation of cyanide adduct of NMNDP+}

The reduced products NMNDPH and NMNTPH were prepared using a modified version of the procedure of Gutcho and Stewart (14). $100 \mu \mathrm{l}$ of the reduction buffer containing $200 \mathrm{mM}$ Tris- $\mathrm{HCl}$, pH 9.0 and $1.2 \%$ (w) sodium hydrosulfite was added to -4 O.D. of the nucleotide. The reaction mixture was heated at $50^{\circ} \mathrm{C}$ for 5 min and immediately cooled on ice. Excess reducing agent was removed by aerating vigorously for $5 \mathrm{~min}$ at $0^{\circ} \mathrm{C}$. The solution was evaporated to dryness and the residue redissolved in an appropriate amount of water. The 4-cyano adduct of $\mathrm{NMNDP}^{+}$ (NMNDP-CN) was prepared by adding $20 \mu \mathrm{l} 0.2 \mathrm{M} \mathrm{KCN}$ to $10 \mu \mathrm{l} 0.1 \mathrm{M} \mathrm{NMNDP}^{+}(\mathrm{pH} 7.0)$. The survival of these products was monitored by UV spectroscopy $(340 \mathrm{~nm})(15)$.

\section{Enzymatic dephosphorylation of nicotinamide nucleotides and oligomers of $\mathrm{NMN}^{+}$}

The mono-, di- and tri-phosphates of nicotinamide nucleoside and the oligomers formed in polynucleotide phosphorylase reaction mixtures were dephosphorylated using calf intestine alkaline phosphatase (CIAP) or phosphodiesterase I (PDE I).

CIAP reaction. A mixture containing $0.5 \mu \mathrm{mol}$ (2.50 O.D.) of the nucleotide $\left(\mathrm{NMN}^{+}, \mathrm{NMNDP}^{+}, \mathrm{NMNTP}^{+}\right.$or oligomers), $1 \times$ phosphorylation buffer $(50 \mathrm{mM}$ Tris- $\mathrm{HCl}, \mathrm{pH} 8.5,0.1 \mathrm{mM}$ EDTA) and $10 \mathrm{U}$ of CIAP in a total volume of $50 \mu \mathrm{l}$ was incubated for an appropriate time at $37^{\circ} \mathrm{C}$.

$P D E$ I reaction. The corresponding nucleotide (2.50 O.D.) was incubated for an appropriate time with $10 \mathrm{U}$ of phosphodiesterase I in a Tris buffer (Tris- $\mathrm{HCl}, 100 \mathrm{mM}, \mathrm{pH} 9.0 ; \mathrm{NaCl}, 100 \mathrm{mM}$; $\mathrm{MgCl}_{2}, 14 \mathrm{mM}$ ) at $25^{\circ} \mathrm{C}$.

The reactions were monitored by TLC in solvent B.

\section{Polynucleotide phosphorylase reactions}

The primer-initiated polynucleotide phosphorylase catalyzed reactions were performed as follows. Each polymerization reaction contained $\sim 2 \mathrm{nM}$ of $5^{\prime}-32 \mathrm{P}$-labelled oligonucleotide as primer and an appropriate concentration of nicotinamide nucleotide in 100 $\mathrm{mM}$ Tris- $\mathrm{HCl}$, pH 9.0 (at $37^{\circ} \mathrm{C}$ ), $25 \mathrm{mM} \mathrm{MgCl}_{2}$ or $\mathrm{MnCl}_{2}$ and 0.5 mM EDTA. The concentration of polynucleotide phosphorylase was $20 \mathrm{U} / \mathrm{ml}$. After an appropriate time at $37^{\circ} \mathrm{C}$, the reactions were quenched by addition of $7.5 \mu \mathrm{l}$ of $0.5 \mathrm{M}$ EDTA, pH 8.0 and then loaded onto an analytical polyacrylamide gel (15\% for the oxidized form and $10 \%$ for the reduced form and cyanide adduct).

The de novo polymerization reactions were carried out under the above conditions, but without primer. The reaction mixtures were extracted with phenol/chloroform to remove the enzyme, passed through a Nensorb column and then lyophilized. The solid was dissolved in TE buffer in preparation for kination. A mixture containing an aliquot of the polymeric product $(0.05$ O.D.), $1 \times$ kinase buffer, $20 \mu \mathrm{Ci}\left[\gamma^{32} \mathrm{P}\right] \mathrm{ATP}$, and $20 \mathrm{U}$ polynucleotide kinase in a total volume of $50 \mu \mathrm{l}$ was incubated at $37^{\circ} \mathrm{C}$ for $1.5 \mathrm{~h}$. The reaction was stopped by addition of $2 \mu \mathrm{l} 0.5$ M EDTA, pH 8.0 and the product was desalted using a Nensorb column. Another aliquot of the polymeric product was first dephosphorylated by CIAP, purified on a Nensorb column and then kinased using the same procedure as above. The final products were analyzed on a $10 \%$ polyacrylamide gel.

\section{Nuclease digestion of products}

Ribomaclease $T 1$ digestion. An aliquot of the purified polymeric product (2000 c.p.m.) was dissolved in a Tris buffer $(5 \mu \mathrm{l})$ containing Tris- $\mathrm{HCl}(0.05 \mathrm{M}, \mathrm{pH} 7.5)$ and EDTA ( $2 \mathrm{mM}, \mathrm{pH} 8.0)$. The solution was incubated at $37^{\circ} \mathrm{C}$ for $5 \mathrm{~min}$. Ribonuclease $\mathrm{T} 1$ $(1 \mu \mathrm{l}, 5 \mathrm{U} / \mu \mathrm{l})$ was added and the reaction mixture was incubated at $37^{\circ} \mathrm{C}$ for $1 \mathrm{~h}$. The resulting solution was mixed with loading buffer $(5 \mu \mathrm{l})$ and then analyzed on a $15 \%$ polyacrylamide gel.

Ribonuclease A digestion. The purified polymeric product ( 2000 c.p.m.) was dissolved in an acetate buffer $(10 \mu \mathrm{l}$, sodium acetate, $50 \mathrm{mM}, \mathrm{pH} 5.0$; tRNA, $0.5 \mathrm{mg} / \mathrm{ml}$ ). After adding ribonuclease A ( $1 \mu \mathrm{l}, 18 \mathrm{U} / \mu \mathrm{l}$ ), the solution was incubated at $37^{\circ} \mathrm{C}$ for $1 \mathrm{~h}$. 


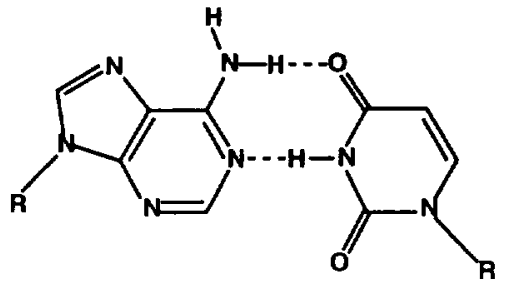

Adenine : Uridine

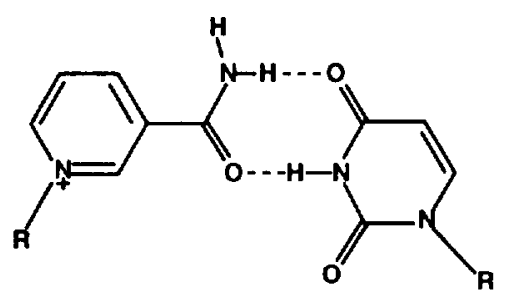

Nicotinamide : Uridine

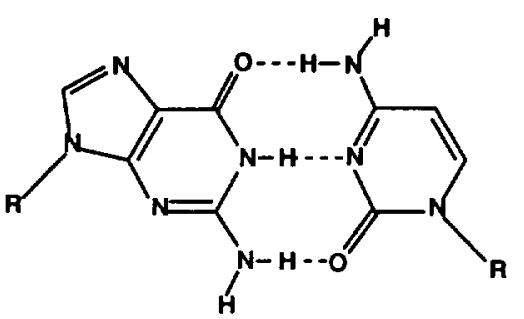

Guanine : Cytosine

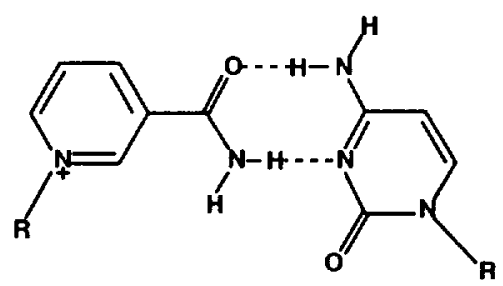

Nicotinamide : Cytosine

Figure 1. Schematic comparison of nicotinamide and purines.

Samples of the resulting solution were evaporated to dryness, redissolved in $3 \mu \mathrm{l}$ of water, mixed with $3 \mu \mathrm{l}$ of loading buffer and subjected to electrophoresis on $15 \%$ polyacrylamide gels.

Phosphodiesterase I digestion. A sample of the purified polymeric product (2000 c.p.m.) was incubated in a Tris buffer $(5 \mu \mathrm{l}$, Tris- $\mathrm{HCl}, 100 \mathrm{mM}, \mathrm{pH} 9.0 ; \mathrm{NaCl}, 100 \mathrm{mM} ; \mathrm{MgCl}_{2}, 14 \mathrm{mM}$ ) with $1 \mathrm{U}$ of phosphodiesterase $\mathrm{I}$ at $25^{\circ} \mathrm{C}$ for $1 \mathrm{~h}$. The reaction was stopped by addition of $\mathrm{I} \mu \mathrm{l}$ of $0.2 \mathrm{M}$ EDTA, $\mathrm{pH} 8.0$ and analyzed on a $15 \%$ polyacrylamide gel as described above.

\section{Terminal transferase reactions}

Terminal deoxynucleotidyl transferase catalyzed addition reactions were carried out according to a procedure of Deng and $\mathrm{Wu}$ (16). An appropriate amount of $5^{\prime}$-labelled primer $\left(\left[{ }^{32} \mathrm{P}\right]-(\mathrm{dA})_{6}\right)$ was incubated with $\mathrm{NMNTP}^{+}$(various concentrations) and terminal transferase $(0.8 \mathrm{U} / \mu \mathrm{l})$ at $37^{\circ} \mathrm{C}$ for $2.5 \mathrm{~h}$ in $2 \mathrm{mM}$ cobalt chloride buffer, $\mathrm{pH} 7.0$. The reactions were stopped by addition of an appropriate amount of EDTA and samples were then subjected to electrophoresis on $20 \%$ polyacrylamide gels.

\section{Transcription reactions}

In vitro transcription reactions were carried out according to the procedure given by Milligan et al. (17). The transcription templates were created by heating a 1:1.2 mixture of complementary single strands (top strand and $18 \mathrm{mer}$ promoter) in TE buffer to $90^{\circ} \mathrm{C}$ for $2 \mathrm{~min}$ and cooling quickly on ice. Each reaction contained $500 \mathrm{nM}$ template and $150 \mathrm{U}$ of T3 or T7 RNA polymerase in $20 \mu \mathrm{l}$ of $40 \mathrm{mM}$ Tris- $\mathrm{HCl}, \mathrm{pH} 8.0$ (at $37^{\circ} \mathrm{C}$ ), 20 $\mathrm{mM} \mathrm{MgCl} 2,0.5 \mathrm{mg} / \mathrm{ml} \mathrm{BSA,} 5 \mathrm{mM}$ DTT, 20 U RNase inhibitor, $1 \mathrm{mM}$ standard nucleoside triphosphates, $5 \mathrm{mM}$ nicotinamide nucleoside triphosphate and $2 \mu \mathrm{Ci}\left[\alpha-{ }^{32} \mathrm{P}\right] \mathrm{UTP}$ or $\left[\gamma^{32} \mathrm{P}\right] \mathrm{GTP}$. Reaction mixtures were incubated at $37^{\circ} \mathrm{C}$ for $2.5 \mathrm{~h}$, quenched by addition of $2.4 \mu \mathrm{l}$ of $0.5 \mathrm{M}$ EDTA, pH 8.0 and loaded on an analytical $20 \%$ denaturing polyacrylamide gel.

\section{Non-enzymatic template-directed reactions}

Template-directed reactions were carried out by a modification of a published procedure $(18)$. First, a solution $(15 \mu \mathrm{l})$ containing 20 $\mu \mathrm{mol} \mathrm{NaCl}, 4 \mu \mathrm{mol} \mathrm{MgCl}$, and 5'-32 P-labelled hairpin oligonucleotide ( $\sim 240000$ c.p.m., $\sim 0.2 \mathrm{pmol})$ was evaporated to dryness. The residue was dissolved in $14 \mu \mathrm{l}$ of $0.286 \mathrm{M} 2,6$-lutidine-HCl buffer, pH 8.0 (at $0^{\circ} \mathrm{C}$ ). The template was annealed by heating at $50^{\circ} \mathrm{C}$ for $3 \mathrm{~min}$, cooling for $3 \mathrm{~min}$ at room temperature and finally cooling to $0^{\circ} \mathrm{C}$ on an ice-bath. Next, $6 \mu \mathrm{l}$ of a freshly prepared solution of the relevant $5^{\prime}$-phosphoro(2-methyl)imidazolides was added and the mixture incubated at $0^{\circ} \mathrm{C}$ for 7 days. The concentration of 2-MeImpG was usually $20 \mathrm{mM}$ and the concentration of the activated nicotinamide nucleotide $100 \mathrm{mM}$. The reaction was stopped by addition of $2.4 \mu \mathrm{l}$ of $0.5 \mathrm{M}$ EDTA, pH 8.0, to $2 \mu \mathrm{l}$ of the reaction mixture. After mixing with $4.4 \mu$ l of loading buffer, the final products were analyzed on a polyacrylamide gel.

\section{RESULTS}

NMNDP' and NMNTP' were identified by UV, [ $\left.{ }^{1} \mathrm{H}\right] \mathrm{NMR}$ and ${ }^{31} \mathrm{PJNMR}$ spectroscopy. The maximum wavelengths of UV absorption of $\mathrm{NMNDP}^{+}$and $\mathrm{NMNTP}^{+}$are identical to that of $\mathrm{NMN}^{+}(19)$. The $\left[{ }^{31} \mathrm{P}\right]$ chemical shifts and coupling constants are similar to those of normal nucleoside diphosphates and triphosphates (data above) (20).

The oxidized forms of the pyridine coenzymes are susceptible to base-catalyzed decomposition, whereas the reduced pyridine nucleotides are labile in acid (21-23). The stabilities of NMNDP+ and NMNDPH were studied under the conditions used in the polynucleotide phosphorylase reaction $\left(25 \mathrm{mM} \mathrm{Mg}^{2+}\right.$ or $\mathrm{Mn}^{2+}$, $\mathrm{pH} 9.0,37^{\circ} \mathrm{C}, 0.5-24 \mathrm{~h}$ ). The results of TLC and UV spectroscopy show that little decomposition of $\mathrm{NMNDP}^{+}$occurs within 


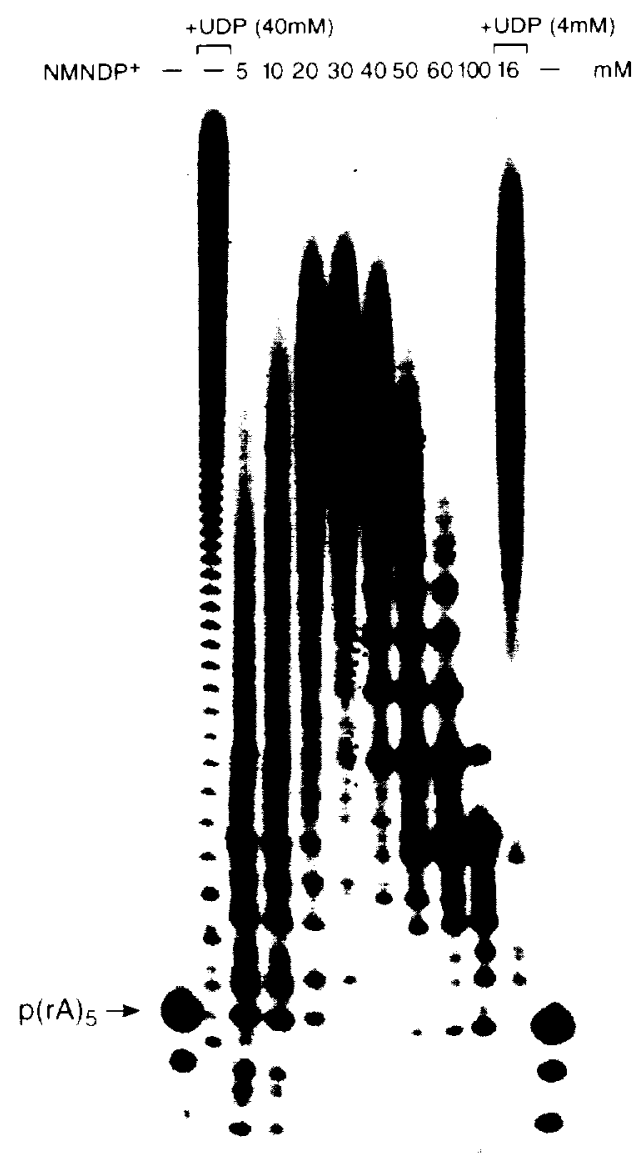

123456789101112

Figure 2. Autoradiogram of the gel electrophoretogram of the products from the polymerization of NMNDPt by polynucleotide phosphorylase primed by $\mathrm{p}(\mathrm{rA})_{5}$ after $24 \mathrm{~h}$ : lane 1 and lane 12, ${ }^{32} \mathrm{P}$-labelled primer. Substrates: lane 2, $40 \mathrm{mM}$ UDP: lanes $3-10,5,10,20,30,40,50,60$ and $100 \mathrm{mM} N M N P^{+}$, respectively; lane $11,4 \mathrm{mM}$ UDP and $16 \mathrm{mM}$ NMNDP+. The concentration of PNPase was $20 \mathrm{U} / \mathrm{ml}$.

the incubation time, but we observed $-30 \%$ decomposition of NMNDPH. In the latter case, a new UV absorption band is observed at $280 \mathrm{~nm}$, presumably due to the presence of a compound in which water is added to the 5-6 double-bond of the nicotinamide ring (24).

\section{Polymerization of $\mathrm{NMNDP}^{+}$by polynucleotide phosphorylase}

Primed polymerization of NMNDP+ was successful in the presence of $\mathrm{Mg}^{2+}$ or $\mathrm{Mn}^{2+}$, but $\mathrm{Mg}^{2+}$ was more efficient than $\mathrm{Mn}^{2+}$ in promoting the formation of long oligonucleotides (data not shown). In typical experiments $2-30$ residues of $\mathrm{NMN}^{+}$are added to the primer. The abnormally large separations between successive bands on the gel indicate that monomers with positive charge are incorporated. The distribution of the product lengths is highly sensitive to the concentration of the substrate (Fig. 2). The optimal concentration of $\mathrm{NMNDP}^{+}$for the formation of longer oligomers is $-25 \mathrm{mM}$. When the $\mathrm{NMNDP}^{+}$concentration is $>60$
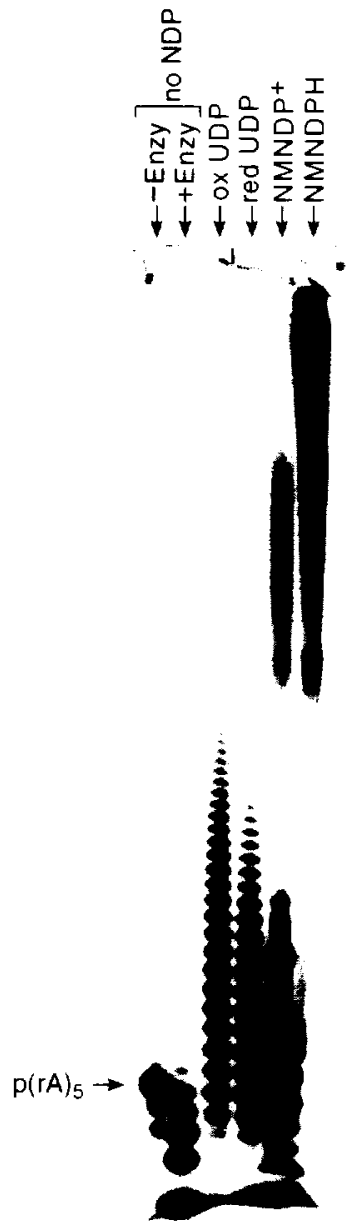

123456

Figure 3. Autoradiogram of the gel electrophoretogram of the products from the polymerization of NMNDPH by polynucleotide phosphorylase using $\mathrm{p}(\mathrm{rA})_{5}$ as primer after $4 \mathrm{~h}$ : lane 1, ${ }^{32} \mathrm{P}$-labelled primer; lane 2, primer incubated with PNPase; lane 3, substrate, 1.5 mM UDP; lane 4, substrate, $1.5 \mathrm{mM}$ UDP in reduction buffer; lane 5 , substrate, $1.5 \mathrm{mM}$ NMNDP+: lane 6 , substrate, 1.5 $\mathrm{mM}$ NMNDPH. The reduction buffer was $1.2 \%$ (w) sodium hydrosulfite in $0.20 \mathrm{M}$ Tris, $\mathrm{pH}$ 9.0. The concentration of PNPase was $20 \mathrm{U} / \mathrm{ml}$.

$\mathrm{mM}$, the majority of the products are very short. When it is significantly $<5 \mathrm{mM}$, there is very little reaction (data not shown).

Extension of the following primers was studied: $(\mathrm{rA})_{2},(\mathrm{rA})_{5}$, $(\mathrm{dA})_{4} \mathrm{rA}$ and $(\mathrm{dA})_{9} \mathrm{rA}$. The optimal reaction conditions are different for different primers. It is found that ( $r A)_{5}$ is the most efficient primer. When $(\mathrm{rA})_{2}$ is used as primer, the major products contain only two or three $\mathrm{NMN}^{+}$residues. The addition of $\mathrm{NMN}^{+}$ to the $3^{\prime}$-terminus of a primer is rapid. When $(\mathrm{rA})_{5}$ is used as primer, the starting material disappears within $1 \mathrm{~h}$ at $37^{\circ} \mathrm{C}$. The yield of longer products increases slowly as the incubation time is extended (data not shown).

In the absence of a primer, we did not detect the de novo polymerization of NMNDP ${ }^{+}$. 


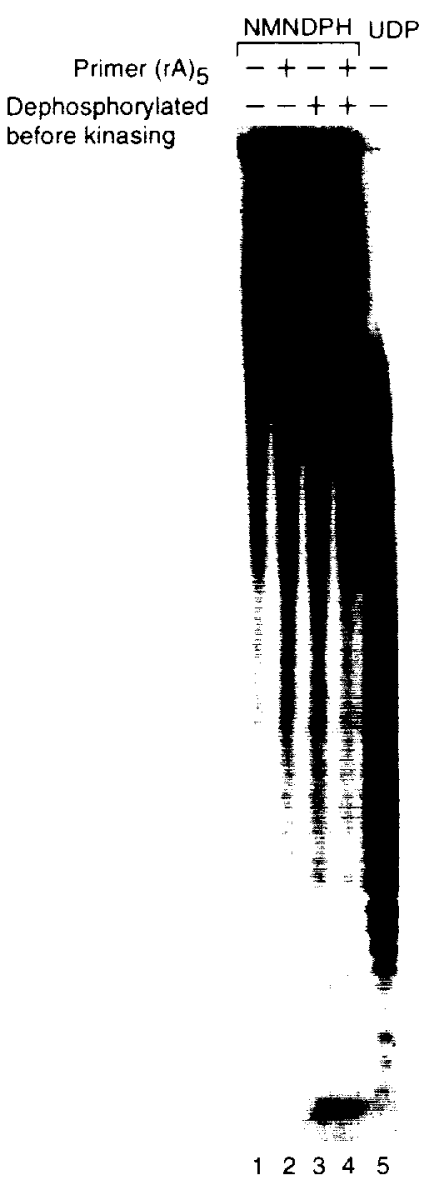

Figure 4. Autoradiogram of the products from the de novo polymerization of NMNDPH by polynucleotide phosphorylase. The polymeric products were kinased directly (lanes 1 and 2) or after dephosphorylation with alkaline phosphatase (lanes 3 and 4).

\section{Polymerization of NMNDPH by polynucleotide phosphorylase}

Figure 3 illustrates the polymerization of NMNDPH by polynucleotide phosphorylase in the presence of $(\mathrm{rA})_{5}$ as primer. In contrast to $\mathrm{NMNDP}^{+}$, NMNDPH is an excellent substrate even at very low concentrations and the length of the products formed is much greater than with $\mathrm{NMNDP}^{+}$. After phenol/chloroform extraction of the product, we found that even on $10 \%$ denaturing polyacrylamide gels, a significant amount of the material remained in the wells. It can be seen from Figure 3 that the distribution of the polymer sizes is broad and that the majority of the products are large polymers ( $>200$ bases). The polymerization rate of NMNDPH in the presence of primer is rapid. The primer disappears within half an hour (data not shown).

NMNDPH is also an excellent substrate for polynucleotide phosphorylase in the absence of a primer. Long oligomeric products that do not move away from the origin of a paper chromatogram are obtained in good yield. However, polymeric products are not detected in this de novo reaction before $8 \mathrm{~h}$, indicating that the initiation of polymerization is slow.

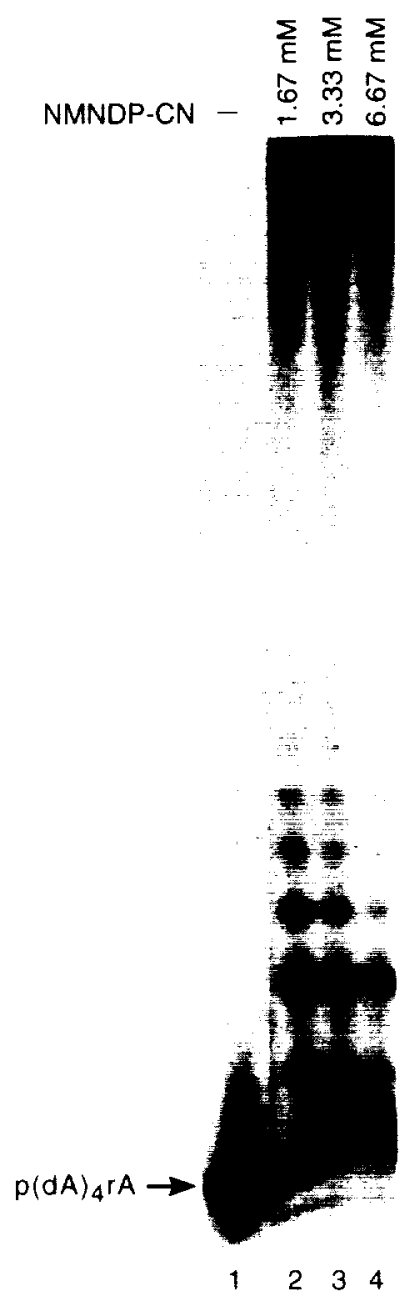

Figure 5. Autoradiogram of the products from the primed polymerization of NMNDP-CN by polynucleotide phosphorylase after $1 \mathrm{~h}$ : lane 1, ${ }^{32} \mathrm{P}$-labelled primer $\mathrm{p}(\mathrm{dA})_{4} \mathrm{rA}$; Substrate: $1.67 \mathrm{mM}$ (lane 2), $3.33 \mathrm{mM}$ (lane 3 ) and $6.67 \mathrm{mM}$ (lane 4) NMNDP-CN. The ratio of the concentration of NDP and $\mathrm{MgCl}_{2}$ was maintained at 2. The concentration of PNPase was $20 \mathrm{U} / \mathrm{ml}$.

Further evidence for the de novo synthesis of high molecular weight poly(NMNDPH) was obtained by high-resolution gel electrophoresis. The purifed products of the polymerization reaction are kinased directly and efficiently by $\mathrm{T} 4$ polynucleotide kinase (Fig. 4), presumably due to the Pi exchange activity of the kinase (25). Essentially the same pattern of products is obtained if the polymeric products are first treated with alkaline phosphatase, reisolated, and then kinased.

\section{Polymerization of the cyanide adduct and the hydration product of NMNDP+ by polynucleotide phosphorylase}

The gel electrophoretogram in Figure 5 illustrates results of the polymerization of NMNDP-CN in the presence of primer. The pattern of products is similar to that obtained from NMNDPH. As in the case of NMNDPH, retention of material at the origin of the electrophoretogram indicates the presence of very high molecular 


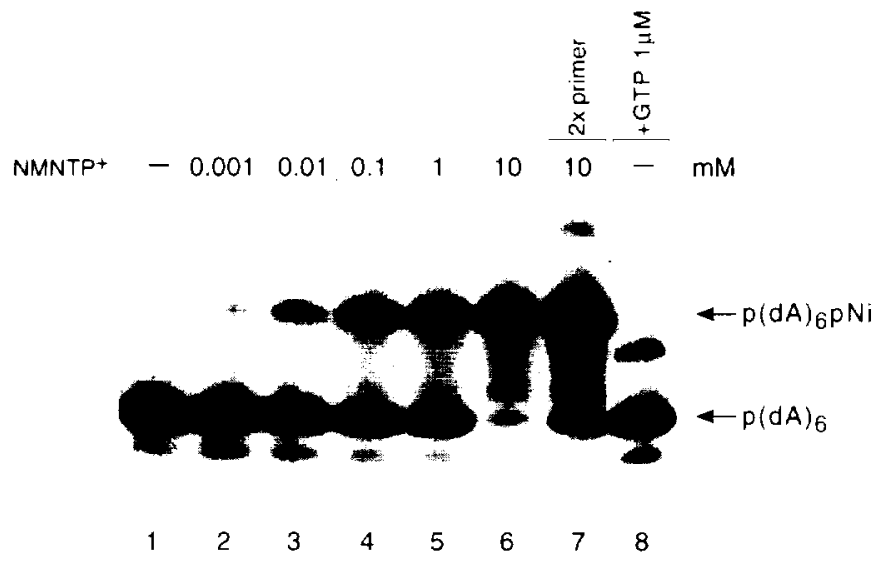

Figure 6. Autoradiogram of the gel electrophoretogram of the products from the addition of $\mathrm{NMNTP}^{+}$to oligodeoxynucleotide $\mathrm{p}(\mathrm{dA})_{6}$ by terminal deoxynucleotidyl transferase after $2.5 \mathrm{~h}$ : lane $1,{ }^{32} \mathrm{P}$-labelled primer. NMNTP+ concentration: $1 \mu \mathrm{M}$ (lane 2), 10 $\mu \mathrm{M}$ (lane 3), 100 $\mu \mathrm{M}$ (lane 4), I mM (lane 5) and $10 \mathrm{mM}$ (lane 6); lane 7, $10 \mathrm{mM} \mathrm{NMNTP+}$ with double the concentration of primer; lane $8.1 \mu \mathrm{M}$ GTP. The concentration of TdT was $0.8 \mathrm{U} / \mu \mathrm{l}$.

weight material. Large polymers were obtained even when we used low concentrations ( $1.67 \mathrm{mM}$ ) of NMNDP-CN as substrate. A broad distribution of polymer sizes was also observed. The rate of polymerization in the presence of primer was even faster than with NMNDPH. Large polymers were present after 5 min and the reaction was essentially complete within $20 \mathrm{~min}$ (data not shown).

The separation between bands in the electrophoretograms (Fig. 5) corresponded to that obtained with $\mathrm{NMNDP}^{+}$rather than NMNDPH, indicating that cyanide dissociates from the polymer prior to the electrophoretic separation. This method, therefore, provides an efficient route to high molecular weight poly $\left(\mathrm{NMN}^{+}\right)$.

Gel electrophoresis and paper chromotagraphy show that the hydration product of $\mathrm{NMNDP}^{+}$is not a substrate of polynucleotide phosphorylase either in the presence or the absence of primer (data not shown).

\section{Addition of $\mathrm{NMNTP}^{+}$to oligodeoxynucleotides by terminal transferase}

Terminal transferase catalyzes the addition of one or two $\mathrm{NMN}^{+}$ residues to an oligodeoxynucleotide primer. The yield of the products is highly dependent on the concentrations of the substrate and primer. When the concentration of the $\mathrm{NMNTP}^{+}$is high enough $(10 \mathrm{mM})$ and the ratio of primer to substrate is appropriate, almost all of the primer is elongated (Fig. 6). The spacing between bands is consistent with the incorporation of monomers carrying a positive charge. The yield of the di-adduct was always small. The purified product terminated by a $\mathrm{NMN}^{+}$ residue can be used to prime the further incorporation of standard nucleotides, but the efficiency is lower than with a standard oligodeoxynucleotide primer (data not shown).

NMNTPH and NMNTP-CN are unstable at $\mathrm{pH} 7$ and cannot, therefore, be used as substrates for terminal deoxynucleotidyl transferase.
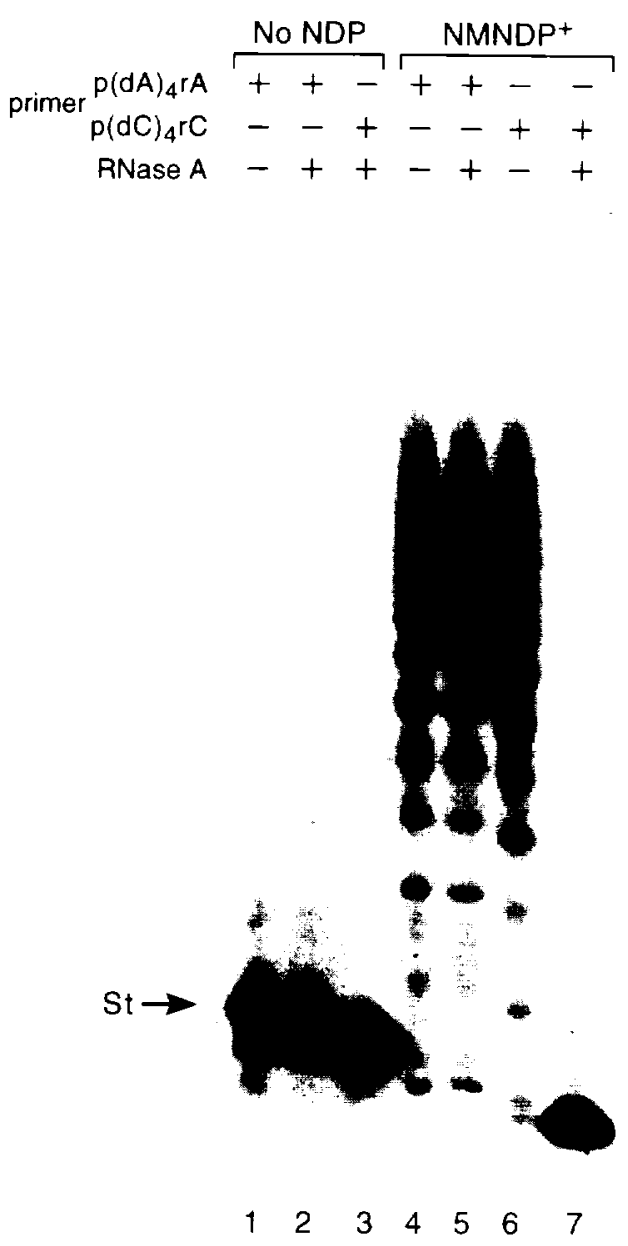

Figure 7. Ribonuclease A analysis of the polymeric products from the primed polymerization of $\mathrm{NMNDP}^{+}$by polynucleotide phosphorylase. The nature of the primer and the substrate for polymerization is indicated at the top of the Figure. $S t$ is the primer $(\mathrm{dA})_{4} \mathrm{rA}$.

\section{Nuclease digestion of products}

We attempted to hydrolyze the products of $\mathrm{NMN}^{+}$addition to different primers with ribonuclease $T 1$, ribonuclease $A$ and phosphodiesterase I. Ribonuclease TI is an enzyme that cleaves $3^{\prime}-5^{\prime}$-phosphodiester linkages adjacent to $G$ residues, generating products terminated with $3^{\prime}$-phosphate and $5^{\prime}$-hydroxyl groups. The products obtained by extending a $(\mathrm{dA})_{4} \mathrm{rA}$ or $(\mathrm{dC})_{4} \mathrm{rC}$ primer with $\mathrm{NMN}^{+}$residues could not be degraded with ribonuclease $\mathrm{T} 1$ (data not shown), showing that $\mathrm{NMN}^{+}$does not substitute for a purine nucleotide in the ribonuclease $\mathrm{T} 1$ catalyzed reaction.

Ribonuclease A cleaves RNA adjacent to a pyrimidine residue generating $3^{\prime}$-phosphate- and 5'-hydroxyl-terminated products. The products of addition of $\mathrm{NMN}^{+}$to a $(\mathrm{dA})_{4} \mathrm{rA}$ primer are not cleaved by ribonuclease A (Fig. 7, lane 5) but the products of addition to a (dC) ${ }_{4} \mathrm{rC}$ primer are completely degraded (Fig. 7, lane 7). Thus $\mathrm{NMN}^{+}$is accepted by RNase $\mathrm{A}$ as a nucleotide analog when it is downstream from a pyrimidine. However, it is not recognized as a pyrimidine analog when it is upstream of a second nicotinamide residue. 

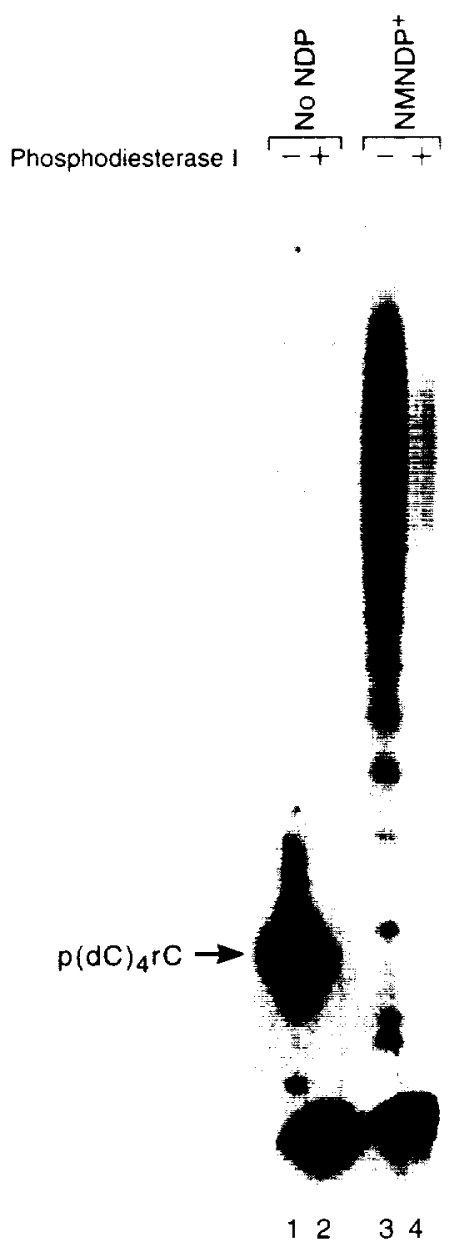

Figure 8. Phosphodiesterase I analysis of the polymeric products from the primed polymerization of NMNDP+ by polynucleotide phosphorylase

Phosphodiesterase I is an exonuclease that degrades RNA from the $3^{\prime}$-terminus. Products in which primers are extended with $\mathrm{NMN}^{+}$residues, are completely degraded by the enzyme (Fig. 8). Thus internucleotide bonds between pairs of $\mathrm{NMN}^{+}$residues are cleaved by phosphodiesterase $\mathbf{I}$.

\section{In vitro transcription reactions and non-enzymatic template-directed reactions}

We attempted to replace each of the nucleoside triphosphates by NMNTP+ or NMNTPH in a variety of transcription reactions using T3 or T7 RNA polymerase. We found no evidence for incorporation of the analogs into products. An extensive series of reactions using a variety of hairpin templates (18) gave no indication that the 2-methylimidazolide derivatives of $\mathrm{NMN}^{+}$in the oxidized or reduced form undergo non-enzymatic template-directed reactions.

\section{DISCUSSION}

$\mathrm{NMNDP}^{+}$and $\mathrm{NMNTP}^{+}$are readily prepared from $\mathrm{NMN}^{+}$by standard procedures (12). Since polynucleotide phosphorylase catalyzes a reversible polymerization of nucleoside $5^{\prime}$-diphos- phates to give polynucleotides and inorganic phosphate, it is important to obtain the nucleoside $5^{\prime}$-diphosphate substrates of polynucleotide phosphorylase free of inorganic phosphate. The separation of $\mathrm{NMNDP}^{+}$from inorganic phosphate on a preparative scale is difficult. Elution from charcoal is inefficient. We achieved an excellent recovery of $\mathrm{NMNDP}^{+}$, free of inorganic phosphate, by using a long DEAE-Sephadex column and eluting with triethylammonium bicarbonate at a low flow rate.

The patterns of products obtained from the primer-initiated oligomerization of $\mathrm{NMNDP}^{+}$with polynucleotide phosphorylase (PNPase) are often complicated and the gels are often badly smeared (Fig. 2). We believe that this is due to the relative instability of the nucleotides and their oligomers under neutral or slightly alkaline conditions. NMNDP+ is fairly stable, but some decomposition by loss of nicotinamide from the nucleotide is expected at $\mathrm{pH} 9(23)$. The modification of one or more residues in an oligomer of $\mathrm{NMN}^{+}$ would give a large number of isomeric products each with a characteristic mobility. This we believe is the origin of multiple bands and of some of the smearing. Loss of nicotinamide during the electrophoretic separation must account for further smearing. Consistent with the latter suggestion, a better-defined gel was obtained at $\mathrm{pH} 7.6$ in the cold room (data not shown).

To confirm this suggestion we isolated from a gel the mono-adduct formed by incubating $(\mathrm{dA})_{6}$ with $\mathrm{NMNTP}^{+}$in the presence of terminal transferase. On re-electrophoresis a new band appeared that migrates close to $(\mathrm{dA})_{6}$ between the positions of $(\mathrm{dA})_{6}$ and $(\mathrm{dA})_{7}$. The position on the gel is consistent with a ribo-adduct of $(\mathrm{dA})_{6}$, formed by the loss of nicotinamide from the $\mathrm{NMN}^{+}$mono-adduct. Furthermore, a smear extends from the mono-adduct band to the new product band consistent with decomposition on the gel (data not shown).

The cyanide adduct of NMNDP', a close analog of NMNDPH, is polymerized by PNPase to give high molecular weight products. The direct synthesis of high molecular weight poly $\left(\mathrm{NMN}^{+}\right)$from NMNDP $^{+}$cannot be achieved with PNPase. However, since NMNDP-CN undergoes polymerization readily and cyanide addition is reversible, high molecular weight poly $\left(\mathrm{NMN}^{+}\right)$is readily obtained by incubating poly(NMNDP-CN) in the absence of cyanide.

NMNDPH and NMNDP-CN are better substrates than $\mathrm{NMNDP}^{+}$for PNPase. This was unexpected. The bond from $\mathrm{N}_{1}$ of the nicotinamide ring to $\mathrm{C}^{\prime}{ }_{1}$ of the ribose in NMNH or NMN-CN would deviate significantly from the plane of the nicotinamide ring (26). Thus NMNH or NMN-CN should have a different geometry from that of standard nucleotides. We anticipated, therefore, that the enzyme would discriminate against the reduced form. Clearly the enzyme is in fact permissive. The relatively ineffective polymerization of $\mathrm{NMNDP}^{+}$cannot be attributed entirely to the positive charge on the ring, since the $5^{\prime}$-diphosphate of 7-methyl guanosine is polymerized efficiently by the enzyme (data not shown).

T4 polynucleotide kinase is known to add phosphate to oligonucleotides even if the 5 -terminal base is heavily modified (27). It is, therefore, not surprising that the enzyme will accept poly(NMNH) as a substrate. The direct labelling of the products from the de novo polymerization of NMNDPH by polynucleotide kinase, without the need for preliminary dephosphorylation, must be the result of the well-known phosphate-transfer reaction catalyzed by the enzyme. Since this is a reaction of oligonucleotides terminated by a $5^{\prime}$-monophosphate, we may conclude that the products of the de novo polymerization of NMNDPH are $5^{\prime}$-monophosphates rather than $5^{\prime}$-diphosphates (28-30). 
The introduction of $\mathrm{NMN}^{+}$residues into RNA is of considerable interest in the context of in vitro RNA evolution. It should be possible to select ribozymes with redox function from random pools of oligodeoxynucleotides terminated by an $\mathrm{NMN}^{+}$residue. The use of terminal transferase to introduce a single $\mathrm{NMN}^{+}$residue at the end of a presynthesized oligodeoxynucleotide should provide the substrates for this kind of selection.

$\mathrm{NMN}^{+}$can, in principle, form hydrogen bonds similar to those formed by adenylic acid or guanylic acid (Fig. 1). However, we were unable to incorporate NMNTP+ into RNA on DNA templates using T3 or T7 RNA polymerase under standard conditions, or in the presence of lowered concentrations of the standard nucleoside triphosphates. Attempts to incorporate $\mathrm{NMN}^{+}$into oligonucleotides in non-enzymatic template-directed reactions were also unsuccessful. These results suggest that $\mathrm{NMN}^{+}$, if it is a molecular fossil of the RNA world, was not an informational unit of a polymer. At first it may have functioned via non-covalent attachment to RNA. Alternatively it could have been attached covalently to RNA by a ribozyme.

\section{ACKNOWLEDGEMENTS}

This work was supported by NSCORT/EXOBIOLOGY Grant No. NAGW-2881 and grant No. NAGW-1600 from the National Aeronautics and Space Administration. We thank Dr Heinz-Peter Muth for communicating preliminary data on the synthesis of $\mathrm{NMNDP}^{+}$and $\mathrm{NMNTP}^{+}$, Aubrey R. Hill, Jr for technical assistance and Sylvia $\mathrm{H}$. Bailey for manuscript preparation.

\section{REFERENCES}

1 Knuger, K., Grabowski, P.J., Zaug, A.J., Sands, J., Gottschling, D.E. and Cech, T.R. (1982) Cell, 31, 147-157.

2 Guerrier-Takada, C., Gardiner, K., Marsh, T., Pace, N. and Altman, S. (198.3) Cell, 35, 849-857.

3 Ziug, A.J. and Cech, T.R. (1986) Biochemistn; 25, 4478-4482.
4 Noller, H.F., Hoffarth, V. and Zimniak. L. (1992) Science. 256. 1416-1419.

5 Piccirilli, J.A., McConnell, T.S., Zaug, A.J., Noller, H.F. and Cech, T.R (1992) Science, 256, 1420-1424.

6 Dai, X., De Mesmaeker, A. and Joyce, G.F. (1995) Science. 267, 237-240.

7 Orgel, L.E. (1968) J. Mol. Biol., 38, 381-393.

8 White III, H.B. (1976) J. Mol. Evol., 7, 101-104

9 Liu, R. and Visscher, J. (1994) Nucleosides Nucleotide's, 13, 1215-1216

10 Joyce. G.F., Inoue, T. and Orgel, L.E. (1984) J. Mol. Biol., 176, 279-306

11 Maniatis, T., Fritsch, E.F. and Sambrook. J. (1982) Molecular Cloming: A Laboratory Mamual. Cold Spring Harbor Laboratory Press, Cold Spring Harbor, NY.

12 Hoard, D. and Ott, D.G. (1965) J. Am. Chem. Soc, 87, 1785-1788.

1.3 Zweig, G. and Shema, J. (1972). Handbook of Chromatography. CRC Press, Cleveland, pp. 162.

14 Gutcho, S. and Stewart. E.D. (1948) Anal. Chem., 20. 1185-1187.

15 Colowick, S.P., Kaplan, N.O. and Ciotti, M.M. (1951) J. Biol. Chem., 191, $447-459$.

16 Deng, G.-r. and Wu, R. (1983) In Wu, R., Grossman, L. and Moldave, K. (eds) Methods in Enzymology, Vol. 100. Academic Press. New York. pp. $96-116$.

17 Milligan, J.F., Groebe, D.R., Witherell, G.W. and Lhlenbeck, O.C. (1987) Nucleic Acids Res., 15, 8783-8798.

18 Wu, T. and Orgel, L.E. (1992) J. Am. Chem. Soc., 114, 318-322.

19 Berghauser, J., Jeck, R. and Pfeifter, M. (1981) Biotech. Lett. 3. 339-344.

20 Cohn, M. and Hughes, T.R., Jr (1960) J. Biol. Chem., 235. 3250-3253.

21 Haas, E. (19.36) Biochem. Z., 288, 123-125.

22 Kaplan, N.O., Colowick, S.P. and Barnes, C.C. (1951) J. Biol. Chem., 191. $461-472$

23 Lowry, O.H., Passoneau, J.V. and Rock, M.K. (1961) J. Biol. Chem., 236. $2756-2759$.

24 Openheimer, N.J. (1982) In Everse, J.. Anderson, B.M. and You, K.-S (eds) The Pyridine Nucleotide Coenzymes. Academic Press, New York. pp $51-89$

25 van de Sande, J.H., Kleppe, K. and Khorana, H.G. (1973) Biochemistry 12. 5050-5055.

26 Glasfeld. A., Zbinden, P., Dobler, M.. Benner, S.A. and Dunit $\iota$, J., D (1988) J. Am. Chem. Soc., 110, 5152-5157.

27 van de Sande, J.H. and Bilsker, M. (1973) Biochemistr, 12, 5056-5062

28 Harvey, R.A. and Grunberg-Manago, M. (1970) Biochem. Bienhys. Re's. Comm., 23, 448-452.

29 Marlier, J.F. and Benkovic, S.J. (1982) Biochenistn: 21. 2349-2356.

30) Sulewski. M.. Marchese-Ragona. S.P., Johnson, K.A. and Benkovic, S.K (1989) Biochemistn, 28, 5855-5864 
